\title{
Engineering Classification of Jointed Rock Mass Based on Connectional Expectation: A Case Study for Songta Dam Site, China
}

\author{
Shengyuan Song, ${ }^{1,2}$ Qiang Xu $\mathbb{D}^{2},{ }^{2}$ Jianping Chen, ${ }^{1}$ Wen Zhang, ${ }^{1}$ Chen Cao, ${ }^{1}$ \\ and Yongchao $\mathrm{Li}^{1}$ \\ ${ }^{1}$ College of Construction Engineering, Jilin University, Changchun 130026, China \\ ${ }^{2}$ State Key Laboratory of Geohazard Prevention and Geoenvironment Protection, Chengdu University of Technology, \\ Chengdu 610059, China
}

Correspondence should be addressed to Qiang Xu; xq@cdut.edu.cn

Received 26 September 2019; Accepted 27 April 2020; Published 20 May 2020

Academic Editor: Yinshan Tang

Copyright (C) 2020 Shengyuan Song et al. This is an open access article distributed under the Creative Commons Attribution License, which permits unrestricted use, distribution, and reproduction in any medium, provided the original work is properly cited.

Engineering classification of complex jointed rock mass is influenced and controlled by many factors with random, nonlinear, and unascertained characteristics, which is an extremely complicated problem. This paper introduces a comprehensive method to classify the rock mass with complex joints. Firstly, evaluation indexes are described by the interval number theory. Secondly, the weight values of the evaluation indexes are determined by the analytic hierarchy process (AHP). Thirdly, the connectional expectation between interval numbers is analyzed and the classification grade of jointed rock mass quality is identified by the set pair analysis theory. The new method can not only describe the dynamic evolution trend of various influencing factors, but also simplify the analysis process of the relationship between interval numbers. The Songta dam abutment rock mass is selected as a study case to verify the rationality of the new method. The classification results of rock mass quality obtained by the new method are in accordance with the actual situation and are consistent with the results provided by the RMR classification.

\section{Introduction}

Jointed rock mass quality is mainly affected by its own structural characteristics (integrity, rock strength, weathering degree, etc.) and its surrounding environment (in situ stress and groundwater), which can generally reflect the engineering geological properties of rock mass within a certain spatial extent [1-3]. Therefore, the classification of rock mass quality should be based on the above influencing factors, and specific indexes should be used to evaluate rock mass properties by qualitative or quantitative methods. In large-scale water conservancy and hydropower projects, reasonable and accurate determination of rock mass classification is not only conducive to the correct selection of mechanical parameters of various rock masses, but also benefit to the optimization of the engineering design and the determination of a reasonable foundation surface $[4,5]$.
The classification of rock mass quality started from underground engineering at first and then gradually expanded to dam foundation engineering. Early methods mostly focused on qualitative or quantitative evaluation of a single index, such as [6] former Soviet Union Ф.М.Садренски classification (1937), Н. Н.Масло classification (1941), Terzaghi classification [7], the dam foundation rock mass classification proposed by the former Soviet Union concrete gravity dam design specification, and the RQD classification introduced by Deere in the United States [8].

In the 1970s, the engineering classification of rock mass gradually developed from the single index to multiindex, qualitative to quantitative evaluation methods. The typical rock mass classification methods for underground engineering are as follows: RSR classification proposed by Wickham et al. [9], the American scholars. RMR 
classification proposed by Bieniawski [10, 11], a Dutch scholar from South Africa, and Q system classification proposed by Barton et al. [12], the Norwegian scholars. These methods are relatively perfect and widely applied to practical engineering.

Compared with underground engineering, rock mass quality classification for dam foundation engineering is not perfect and is still in exploration. The representative rock mass quality classification methods for dam foundation engineering abroad are as follows [6]: R. P. Miller's classification scheme, the classification scheme for inhomogeneous rock mass proposed by the Spanish scholars Kikuchi et al. [13], and the dam foundation rock mass classification system introduced by a Japanese scholar Kikuhiro.

In China, the research on rock mass classification of dam foundation engineering started relatively late. The representative classification methods are as follows: rock mass quality coefficient $\mathrm{Z}$ classification proposed by $\mathrm{Gu}$ and Huang [14], rock mass quality index M classification proposed by Yang [15], the YZP classification of the Three Gorges Project proposed by the Yangtze River Commission [16], standard for engineering classification of rock masses (GB50218-94) [17], and code for water resources and hydropower engineering geological investigation (GB5028799) [18] are proposed, respectively.

Generally speaking, the rock mass classification is gradually developing from qualitative to quantitative on the basis of engineering practice. GB50287-99 is successfully applied to the Laxiwa Hydropower Station, and the dam foundation rock mass is reasonably divided into 5 major grades and 7 subgrades $[19,20]$. Due to the particularity of columnar jointed basalt developed in the Baihetan Hydropower Station, RMR, Q, GB50218-94, and GB50287-99 are synthetically used for rock mass quality classification. However, the results obtained by the above four methods are not exactly consistent. Finally, the quality grade of the rock mass is determined through comprehensive analysis and comparison $[21,22]$. With the increase for the scale of engineering rock mass and the complexity of its occurrence environment, the practicability of the traditional rock mass classification method is limited.

Since the 1990s, researchers at home and abroad have gradually realized that the influencing factors of rock mass quality have the characteristics of fuzziness. Habibagahi and Katebi adopt the fuzzy set theory to classify rock mass quality [23]. Yuan et al. proposed a multiindex rock mass quality evaluation method based on extension theory [24]. Cao and Zhang introduced the idea of variable weight processing into rock mass quality evaluation and established a fuzzy evaluation method of rock mass quality based on variable weight [25]. In the engineering classification of jointed rock mass, the aforementioned method fully considers the fuzziness of influencing factors. However, rock mass quality evaluation is to evaluate the engineering geological properties of rock mass in a certain space, which contains a large number of stochastic joints. The geometric, mechanical, and hydraulic properties of these joints often change in a certain range. That is to say, the factors affecting rock mass quality classification have the characteristics of interval numbers.
Therefore, this paper attempts to use interval numbers to express the influencing factors of rock mass quality and then applies set pair analysis theory to analyze the connectional expectation between interval numbers and determine the quality grade of rock mass.

\section{Theory for the Connectional Expectation}

2.1. Interval Number Theory. Objectively speaking, the development of the fractures in complex rock mass is due to anisotropy and randomness. In addition, limited field outcrop and incomplete survey information will lead to the lack of data. Hence, the original data indicating the engineering geological properties of complex fractured rock mass are often not a certain number but some interval numbers. Subjectively speaking, engineers have a deeper understanding for fractured rock mass and will not stay at a single point. Therefore, engineers need to use interval numbers to quantify the engineering geological properties of the fractured rock mass.

Usually, an interval number can be used to represent a certain attribute of the research object, which is defined as follows [26-28].

Assume that any $x^{-}$and $x^{+}$belong to the set $\mathrm{R}$ of real numbers, and $x^{-} \leq x^{+}$. Then, a standard interval number can be expressed as $[X]=\left[x^{-}, x^{+}\right]$, where $x^{-}$is the minimum value of the interval number and $x^{+}$is the maximum value of the interval number. If $x^{-}>0$, then $[X]$ is called a positive interval number. If $x^{+}<0$, then $[X]$ is called a negative interval number. If $x^{-}<0$ and $x^{+}>0$, then $[X]$ is called a difference interval number. If $x^{-}=x^{+}$, then the interval number $[X]$ degenerates to an ordinary real number $X$. The expectation of interval numbers can be expressed as:

$$
E[(X)]=x_{1} p_{1}+x_{2} p_{2}+\cdots+x_{t} p_{t}
$$

where $x_{1}, x_{2}, \ldots, x_{t}$ are the measured values describing a certain attribute of the research object, $x_{1}, x_{2}, \ldots, x_{t} \in[X]$, and $p_{1}, p_{2}, \ldots, p_{t}$ are the probability values of the measured value $x_{1}, x_{2}, \ldots, x_{t}$.

The study of interval number theory is not perfect, and its application is not very mature. Especially the problem of comparison and connection between two or more interval numbers is very difficult to solve. This study will try to use set pair analysis theory to analyze the connection problem between interval numbers.

2.2. Set Pair Analysis Theory. In nature, the same thing has both certainty and uncertainty. From a philosophical point of view, they are a pair of contradictions, both opposition and same. That is to say, certainty and uncertainty of things can be transformed into each other under certain conditions. Set pair analysis theory is precisely the mathematical theory used to deal with the interaction between certainty and uncertainty. This theory was proposed by Zhao, a mathematician in China. Set pair and connection degree are the main concepts of the set pair analysis theory. If the known sets $[X]$ and $[Y]$ have a certain connection, then the two sets can be integrated into a pair, which is expressed as a set pair 
$\widehat{H}=(X, Y)[29]$. The same, difference, and opposition between the two sets can be expressed by the connection degree $\mu_{(X, Y)}$. The specific formula is as follows [30]:

$$
\mu_{(X, Y)}=a+b i+c j,
$$

where $i$ is the coefficient of difference, $-1 \leq i \leq 1 ; j$ is the coefficient of opposition, generally $j=-1 ; a, b$, and $c$ separate represent the same degree, difference degree, and opposition degree between the evaluation index $X_{p j}$ of sample $X_{p}$ and rock mass quality grade $k$, and $a+b+c=1$ (Figure 1).

In the uncertain evaluation of things, the interval number form of the $n$th index value of the evaluation sample $m$ is $\left[X_{m n}\right]=\left[x_{m n}^{-}, x_{m n}^{+}\right]$and the corresponding expectation can be calculated according to formula (1). Similarly, the grading standard of evaluation index can also be expressed by the interval number. The interval number form of the $k$ th grade of the $n$th index is $\left[Y_{n, k}\right]=\left[y_{n, k}^{-}, y_{n, k}^{+}\right]$, and the corresponding expectation is $E\left[Y_{n, k}\right]$. The measured data and grade interval of the evaluation index can form a set pair. The evaluation criteria for the same, difference, and opposition of the set pair is as follows: if the measured data $\left[X_{m n}\right]$ are completely within the grade interval $\left[Y_{n, k}\right]$, i.e., $x_{m n}^{-}>y_{n, k}^{-}$ and $x_{m n}^{+}<y_{n, k}^{+}$, then the sample $\left[X_{m n}\right]$ and the grade $\left[Y_{n, k}\right]$ are in the same relationship. If the measured data $\left[X_{m n}\right]$ are completely outside the grade interval $\left[Y_{n, k}\right]$, i.e., $x_{m n}^{-}>y_{n, k}^{+}$ or $x_{m n}^{+}<y_{n, k}^{-}$, then the sample $\left[X_{m n}\right]$ and the grade $\left[Y_{n, k}\right]$ are in opposition relationship (Figure 2). In addition to the above two relationships, the sample $\left[X_{m n}\right]$ and the grade $\left[Y_{n, k}\right]$ are in difference relationship [31].

Usually, the evaluation indexes of the sample are divided into two types, namely, cost-type and benefit-type. The benefit-type index refers to the index whose value increases in the same direction as the grade increases. However, the cost-type index is just the opposite. Regarding the connectional expectation, the cost-type index can be calculated according to formula (3) and the benefit-type index can be calculated according to formula (4) [32]:

$$
\begin{aligned}
& \mu\left(\left[X_{m n}\right],\left[Y_{n, k}\right]\right)= \begin{cases}\frac{E\left(\left[X_{m n}\right]\right)-y_{n, k}^{-}}{y_{n, k}^{-}-y_{n, k+1}^{-}}, & \left(y_{n, k+1}^{-} \leq E\left(\left[X_{m n}\right]\right)<y_{n, k}^{-}\right), \\
\frac{E\left(\left[X_{m n}\right]\right)-y_{n, k}^{-}}{E\left(\left[Y_{n, k}\right]\right)-y_{n, k}^{-},} & \left(y_{n, k}^{-} \leq E\left(\left[X_{m n}\right]\right)<E\left(\left[Y_{n, k}\right]\right)\right), \\
\frac{E\left(\left[X_{m n}\right]\right)-y_{n, k}^{+}}{E\left(\left[Y_{n, k}\right]\right)-y_{n, k}^{+},} & \left(E\left(\left[Y_{n, k}\right]\right) \leq E\left(\left[X_{m n}\right]\right)<y_{n, k}^{+}\right), \\
\frac{y_{n, k}^{+}-E\left(\left[X_{m n}\right]\right)}{y_{n, k-1}^{+}-y_{n, k}^{+}}, & \left(y_{n, k}^{+} \leq E\left(\left[X_{m n}\right]\right)<y_{n, k-1}^{+}\right), \\
-1, & \text { (other), }\end{cases} \\
& \mu\left(\left[X_{m n}\right],\left[Y_{n, k}\right]\right)= \begin{cases}\frac{E\left(\left[X_{m n}\right]\right)-y_{n, k}^{-},}{y_{n, k}^{-}-y_{n, k-1}^{-}}, & \left(y_{n, k-1}^{-} \leq E\left(\left[X_{m n}\right]\right)<y_{n, k}^{-}\right), \\
\frac{E\left(\left[X_{m n}\right]\right)-y_{n, k}^{-}}{E\left(\left[Y_{n, k}\right]\right)-y_{n, k}^{-}}, & \left(y_{n, k}^{-} \leq E\left(\left[X_{m n}\right]\right)<E\left(\left[Y_{n, k}\right]\right)\right), \\
\frac{E\left(\left[X_{m n}\right]\right)-y_{n, k}^{+},}{E\left(\left[Y_{n, k}\right]\right)-y_{n, k}^{+}} & \left(E\left(\left[Y_{n, k}\right]\right) \leq E\left(\left[X_{m n}\right]\right)<y_{n, k}^{+}\right), \\
\frac{y_{n, k}^{+}-E\left(\left[X_{m n}\right]\right)}{y_{n, k+1}^{+}-y_{n, k}^{+},} & \left(y_{n, k}^{+} \leq E\left(\left[X_{m n}\right]\right)<y_{n, k+1}^{+}\right), \\
-1, & \text { (other), }\end{cases}
\end{aligned}
$$




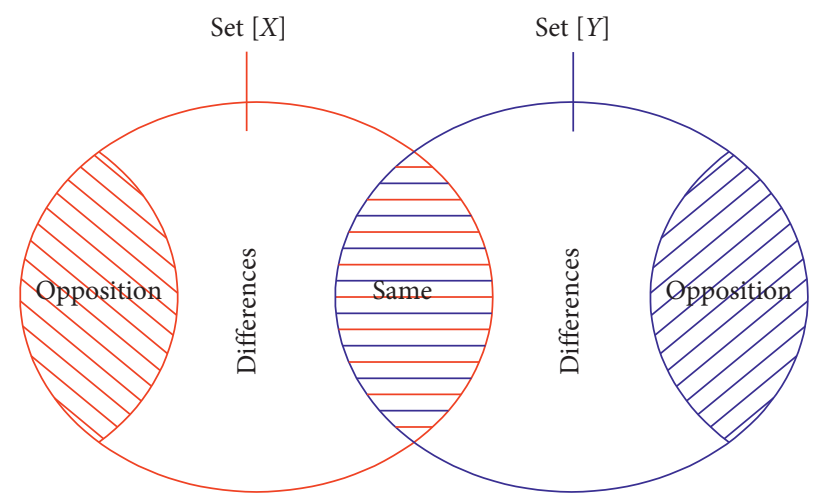

Figure 1: Same, difference, and opposition relationships of a set pair.
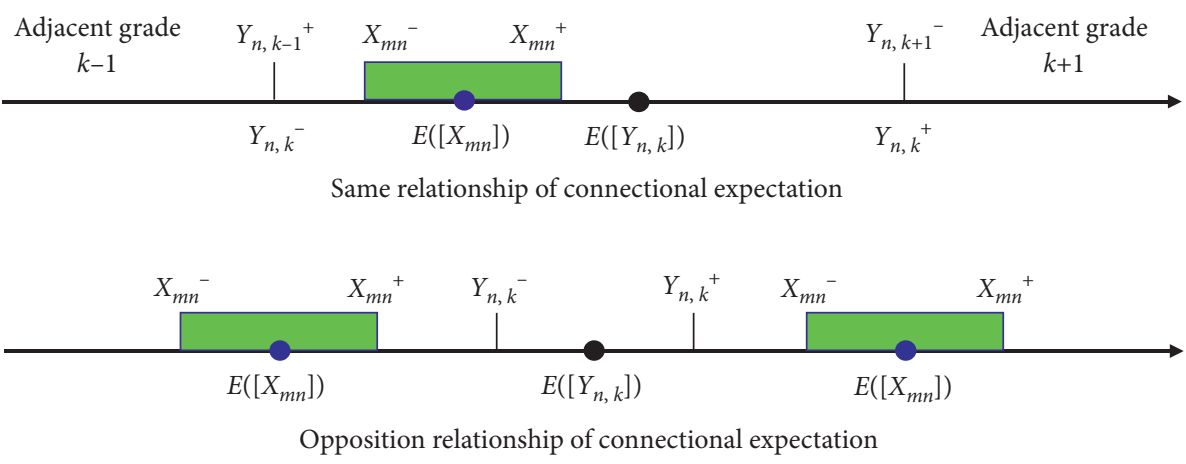

Figure 2: Diagram for same and opposition relationships of connectional expectation.

where $\mu\left(\left[X_{m n}\right],\left[Y_{n, k}\right]\right)$ is the connectional expectation of the $n$th index of the $m$ th sample with respect to the evaluation grade $k$. When the weight value of the $n$th index is $W_{n}$, then the integrated connectional expectation of the $m$ th sample with respect to the evaluation grade $k$ is:

$$
\mu_{\mathrm{m}, k}=\sum_{n=1}^{N} W_{n} \mu\left(\left[X_{m n}\right],\left[Y_{n, k}\right]\right) .
$$

If

$$
\mu_{\mathrm{m}, k_{0}}=\max \left\{\mu_{m, k} \mid k=1,2, \ldots, k\right\} .
$$

Then, the evaluation grade of this sample is $k_{0}$.

\section{The Case Study}

3.1. Study Area. The Songta Hydropower Station will be built on the main stream of the Nu River, which is the first cascade hydropower station in the hydropower development scheme for the $\mathrm{Nu}$ River. The dam site is located in Songta Village, Chayu County, Tibet in China, about $7 \mathrm{~km}$ distance from the boundary between Yunnan and Tibet along the main stream of the $\mathrm{Nu}$ River. The flow direction of the $\mathrm{Nu}$ River at the dam site is $188^{\circ} \mathrm{SW}$ (Figure 3).

The upstream basin of the dam site is vast and the water flow is large. The area of the basin reaches $1035,000 \mathrm{~km}^{2}$, and the annual runoff reaches 39.1 billion $\mathrm{m}^{3}$. The concrete double-curved arch dam with a design height of $318 \mathrm{~m}$ is planned to be built. The total storage capacity is 4.547 billion $\mathrm{m}^{3}$, and the installed capacity is $3600 \mathrm{MW}$.

The dam site is a typical mountain-canyon geomorphology, and the valley exhibits an asymmetric " $V$ " shape. The overall slope of the river bank is approximately $50^{\circ}$ (Figure 4(a)). The river bank at the dam site is composed by two types of lithology: biotite monzonitic granite and plagioclase amphibolite from the Yanshanian (Cretaceous) period. The biotite monzonitic granite is the predominant lithology, which is primarily comprised of quartz, plagioclase, potassium feldspar, and biotite. The plagioclase amphibolite is intruded as dykes with a width $0.05-5 \mathrm{~m}$ into the biotite monzonitic granite. Under the action of extrusion, some stochastic joints are formed within the above rock masses (Figure 4(b)).

3.2. Data Acquisition and Analysis. In order to ascertain the engineering geological condition of the rock mass at the dam site, some adits are excavated at different elevations of the dam abutment. The strike of these adits is basically perpendicular to the flow direction of the $\mathrm{Nu}$ River. The commonly used window sampling method is adopted to investigate the joint information outcropped within the adit. Joint information collected includes orientation, rock strength, spacing, RQD, roughness, aperture, weathering, and groundwater.

In the study, the adits PDS1, PD222, PD224, and PD226 located at the right dam abutment are chosen as the study 


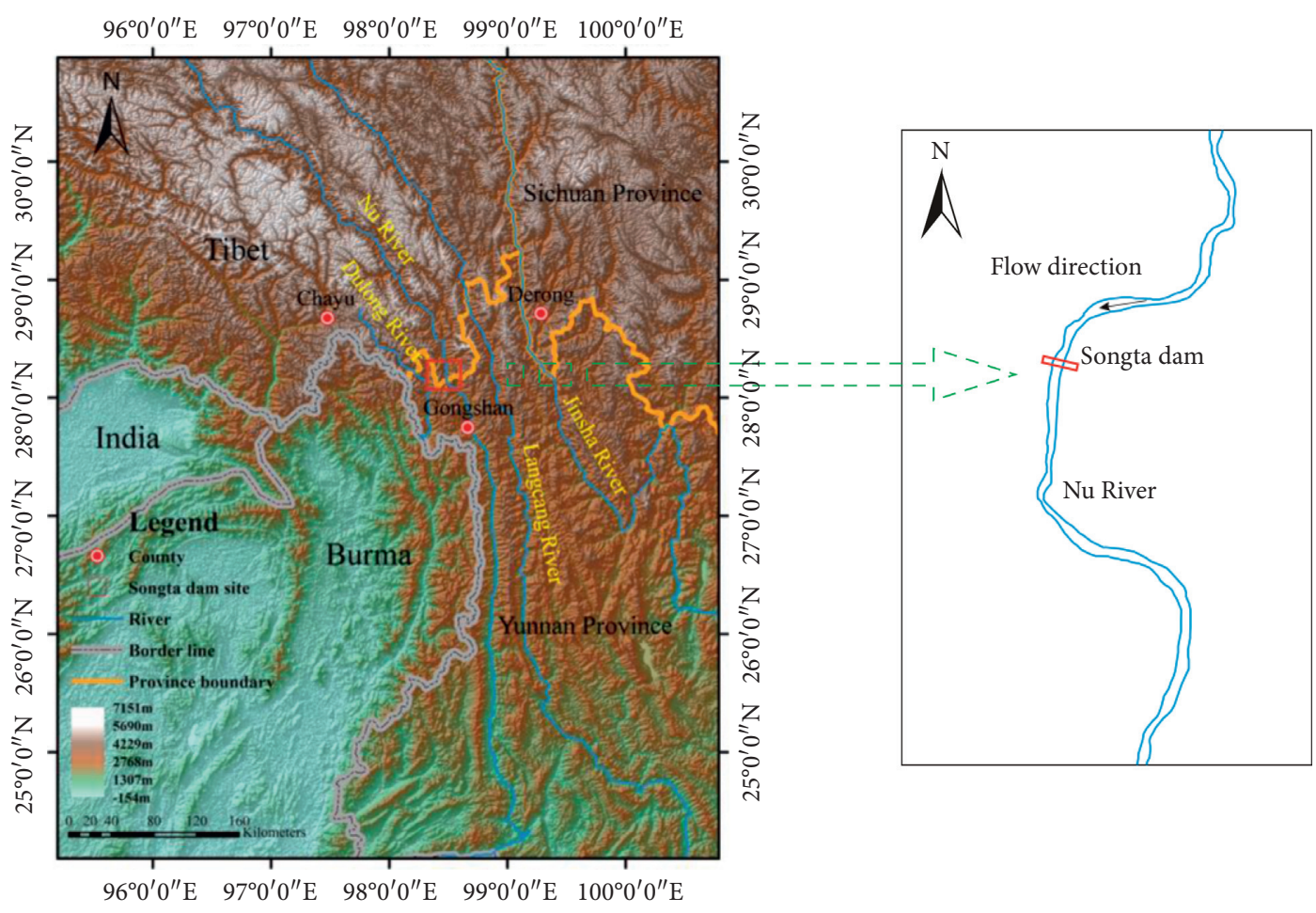

FIgURE 3: Topographic and location map of the study case.

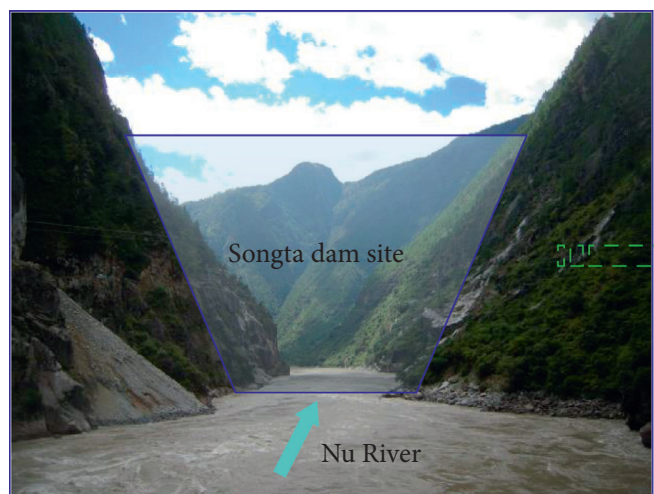

(a)

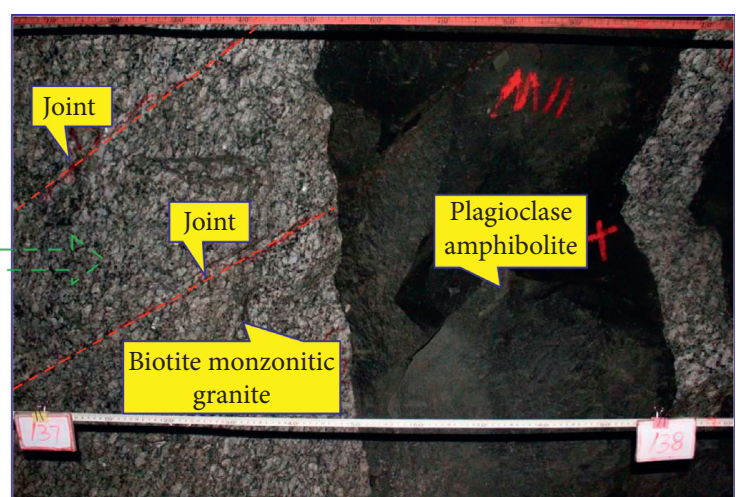

(b)

FIgURE 4: Geological conditions of the Songta dam site.

case for the rock mass classification. The adits PDS1, PD222, PD224, and PD226 are located at elevations of $1716.7 \mathrm{~m}$, $1765.9 \mathrm{~m}, 1814.9 \mathrm{~m}$, and $1863.9 \mathrm{~m}$, respectively. The lengths of adits PDS1, PD222, PD224, and PD226 are 200 m, $200 \mathrm{~m}$, $150 \mathrm{~m}$, and $150 \mathrm{~m}$, respectively. The distribution map of the above adits is shown in Figure 5(a).

The adit outcrops display that the properties of joints developed within the rock mass varied with the horizontal distance from the valley slope. According to the engineering geological condition of the outcrop surface within adits and the joint formation mechanism of the unloading zone in the high slope of the river valley [33], the rock mass around the adits is divided into three sections from the slope surface to the slope interior (Figure 5(b)):

(i) Section 1: this area is located on the surface section of the valley slope. In the section, in situ stress is significantly reduced and the rock mass is highly weathered. Joints are abundantly developed within the rock mass. Joints inclined to the slope surface at gentle dip angles have a dominant advantage, and these joints are filled with clay mud. 


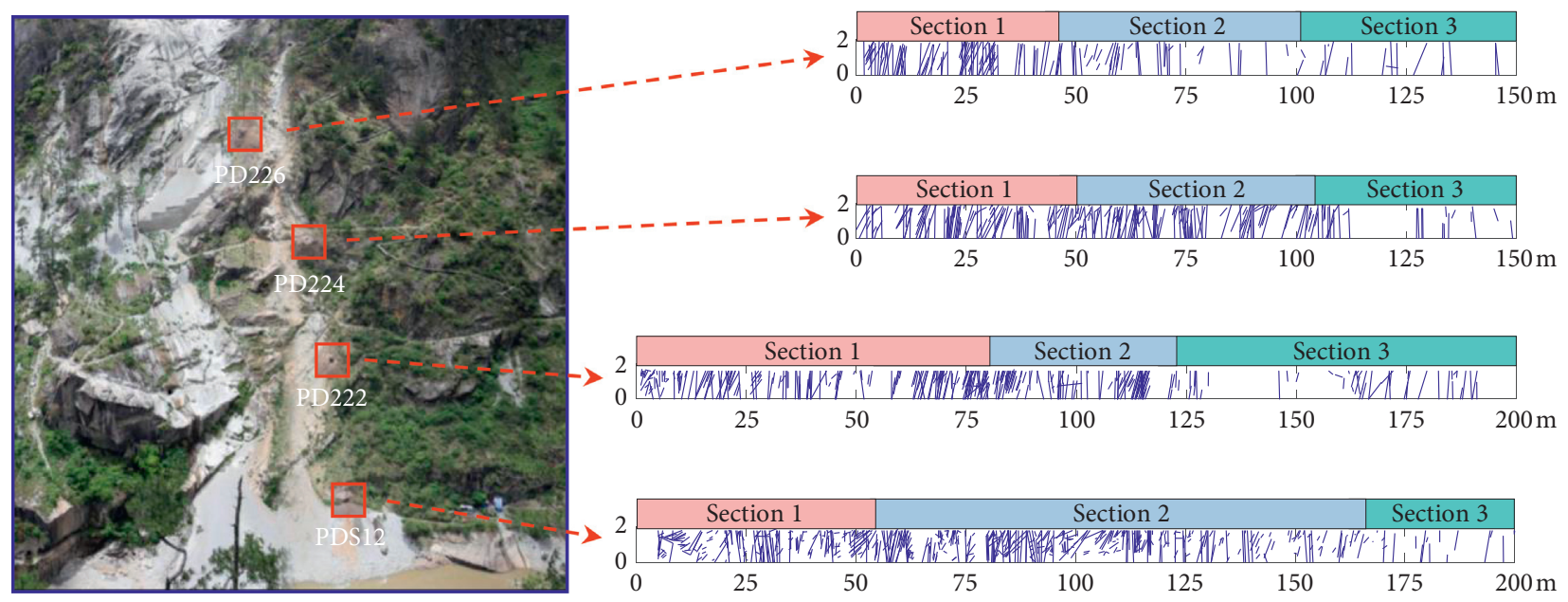

(a)

(b)

Figure 5: The distribution map of the adits (a) and the sectional map of the rock mass around the adits (b).

(ii) Section 2: in situ stress increases gradually, and rock mass is moderately and slightly weathered. Joints develop randomly within the rock mass, and joint density decreases gradually. Only a small amount of joints with gentle dip angles are filled with clay.

(iii) Section 3: in situ stress is basically stable, and rock mass is fresh. Joints seldom develop within the rock mass.

To ascertain the dominant orientation of the joints within each section of each adit, the joint sets within each section are identified according to an improved FCM method proposed by Song et al. [34]. The dominant joint sets of each section in each adit are shown in Figure 6. The figure exhibits that the joints in each section are divided into three groups. Set 1 is the joint dipping towards the slope surface at a gentle dip angle. Set 2 and Set 3 are joints with a steep dip angle. In section 1 of each adit, the number of joints in Set 1 is much larger than that in Set 2 and Set 3. In section 3 of each adit, the number of joints in each group is basically equal.

\subsection{Rock Mass Quality Evaluation Model Based on Connec-} tional Expectation. In this paper, engineering classification of jointed rock mass based on connectional expectation is the comprehensive method. The new method combines three mathematical methods to solve complex decisionmaking problems affected by various uncertainties. Firstly, interval number theory is adopted to represent the evaluation indexes of rock mass quality. Secondly, AHP is utilized to determine the weight values of evaluation indexes. Thirdly, set pair analysis theory is used to analyze the connectional expectation between interval numbers and determine the quality grade of rock mass. The flowchart of the new method is shown in Figure 7.

3.4. Selection of Evaluation Index. In order to obtain more reasonable and accurate results for rock mass quality evaluation, it should be as comprehensive and scientific as possible when selecting the evaluation index. Table 1 lists the main indexes considered in the 7 typical methods for rock mass quality evaluation at home and abroad. It can be seen from the table that the indexes considered by the 7 typical methods are not identical. The indexes considered six or more times are rock strength (7 times), joint spacing (6 times), joint state (6 times), and groundwater (6 times). This indirectly indicates that the above indexes are the main indexes affecting the engineering geological characteristics of jointed rock mass.

Referring to the main influencing factors of rock mass quality evaluation commonly used by experts at home and abroad and combining with the rock mass structure characteristics of the Songta dam site, this paper synthetically selected eight indexes to classify the quality of dam abutment rock mass. These eight indexes include rock strength, joint spacing, RQD, roughness, aperture, weathering, groundwater, and dip difference. The dip difference refers to the difference between the dominant dip angle of the joint set dipping towards the slope surface and the dip angle of the slope surface.

When collecting joint information, roughness, aperture, weathering, and groundwater are qualitatively described. These qualitative indexes are inconvenient to participate in the calculation of rock mass classification grade. Hence, roughness, aperture, weathering, and groundwater are quantified according to qualitative description. The quantitative values of the above indexes are shown in Table 2. On this basis, evaluation indexes of rock mass in adits PDS1, PD222, PD224, and PD226 are expressed by the interval number and are shown in Table 3.

3.4.1. Determination of Evaluation Grade Criteria. Before determining the quality grade of rock mass, it is necessary to establish a single index evaluation system for influencing factors of rock mass quality. This paper mainly refers to the classification criteria commonly used at home and abroad, 


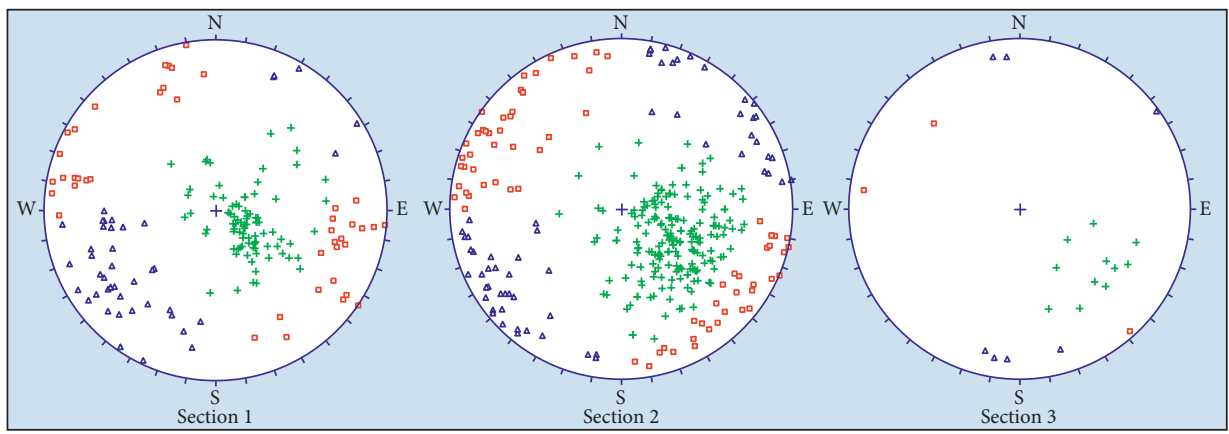

(a)

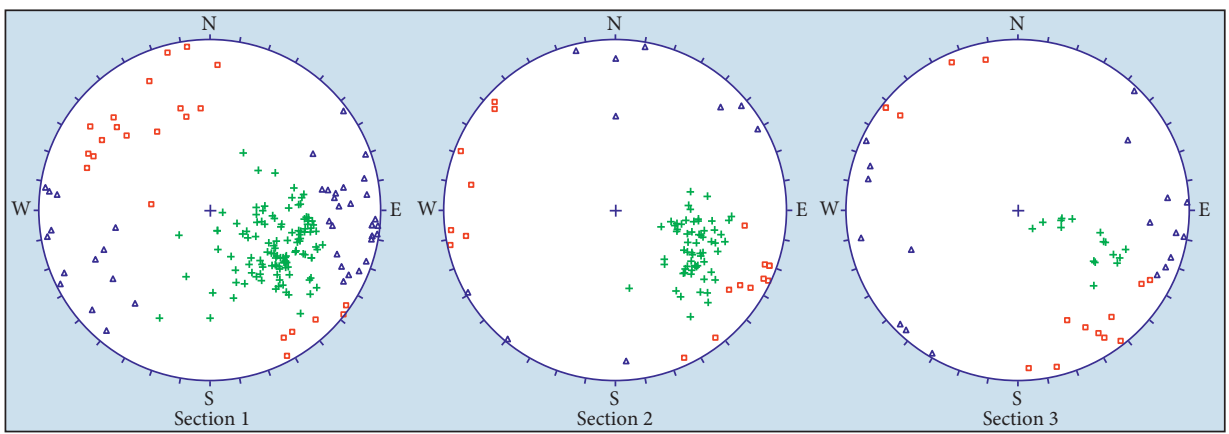

(b)
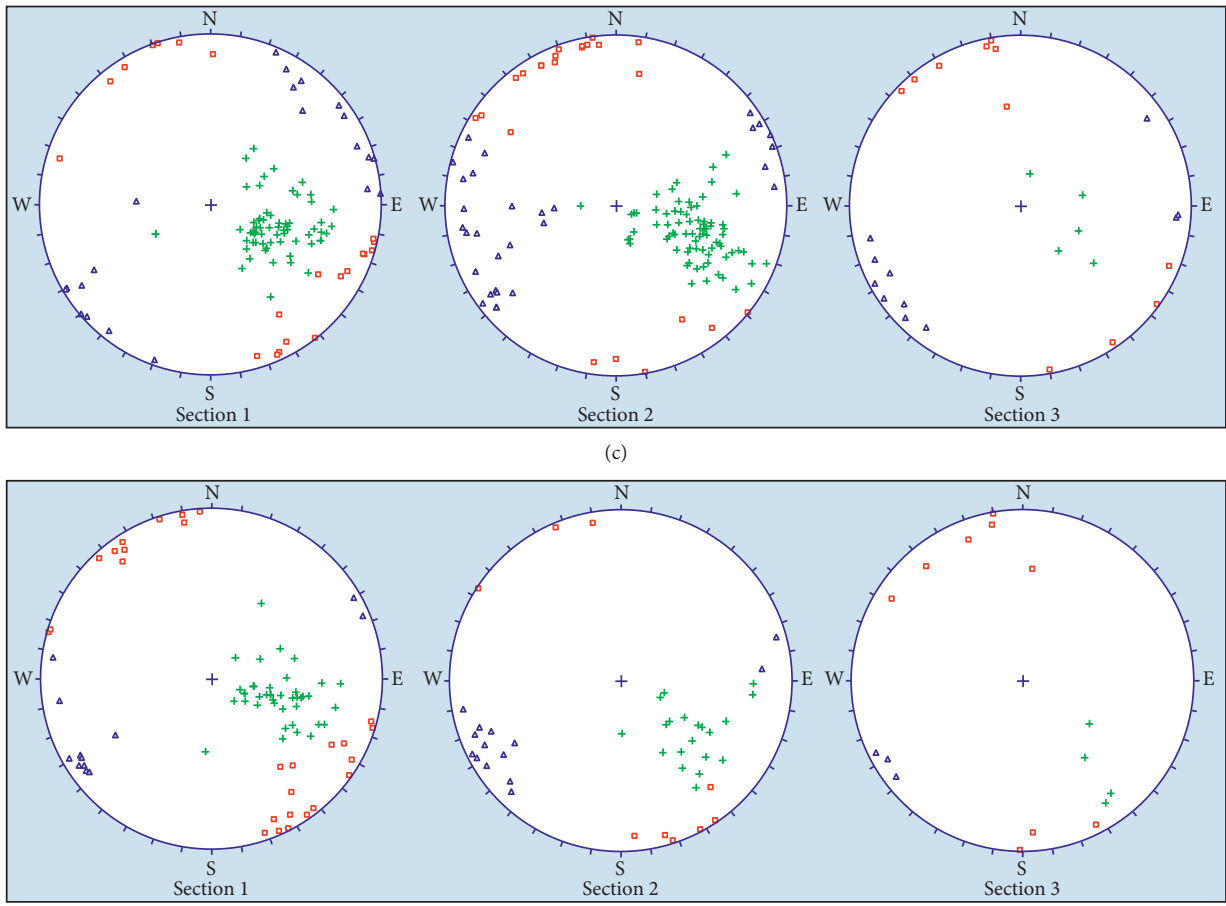

(d)

+ Set 1

口 Set 2

Figure 6: The dominant joint sets of each section in each adit. (a) PDS1. (b) PD222. (c) PD224. (d) PD226.

such as RQD classification, RMR classification, China's national code for water resources, and hydropower engineering geological investigation (GB50287-99) $[8,10,18]$, and comprehensively considers the development characteristics of joints in the study area. In addition, combining the quantitative values of each index in Table 2, a single 


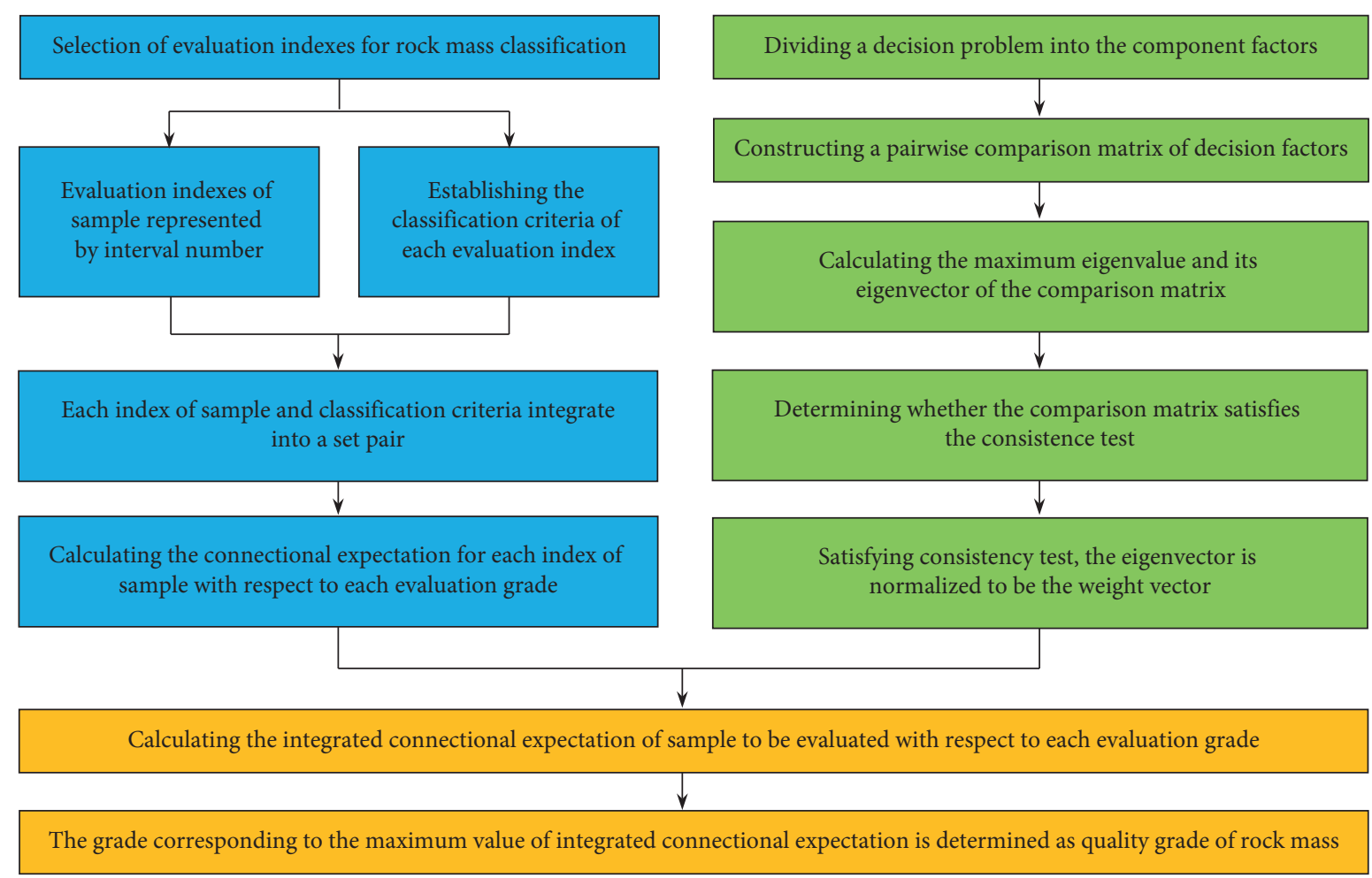

FIGURE 7: Flowchart for the rock mass quality evaluation model based on connectional expectation.

index evaluation system for rock mass quality is established as given in Table 4 .

\subsubsection{Calculation for Weight of Evaluation Index.} Through the analysis of eight evaluation indexes, it can be seen that each evaluation index has a very important impact on rock mass quality, but the impact degree of each evaluation index is different. That is to say, the weight value of each evaluation index is different. Only when the impact degree (weight value) of the index is taken into account in the evaluation of rock mass quality, can a reasonable evaluation result be obtained. In this section, analytic hierarchy process (AHP) will be used to consider the impact of each evaluation index on rock mass quality and to calculate its weight value.

AHP is one of the most commonly used methods of weight assignment. It is a multiobjective decision analysis method that combines qualitative and quantitative research as proposed by an American scholar Saaty [35]. The basic idea of this method is to hierarchize and quantify complex decision problems according to human thinking process and then make multicriteria decision-making on this basis. Its characteristic is that less quantitative information is used to mathematize the decision-making process under the premise of fully excavating the essence of complex decision problems. The major steps of the AHP method are as follows $[36,37]$ :

(1) According to the factors involved in a complex decision problem and its membership relations, the decision problem is divided into the component factors and a hierarchical structural model is established. The hierarchical structural model of rock mass classification established in this paper is shown in Figure 8.

(2) Assigning numerical values to each factor based on the subjective judgment for the relative importance of each factor, a pairwise comparison matrix of decision factors is constructed. The construction standard of the comparison matrix is based on the 1-9 scale method, which is shown in Table 5. When the factor on the vertical axis is more important than the factor on the horizontal axis, the value varies between 1 and 9. Conversely, the value varies between the reciprocals $1 / 2$ and $1 / 9$. The pairwise comparison matrix for evaluation indexes of rock mass quality is constructed, as shown in Table 6.

(3) The maximum eigenvalue of the comparison matrix and its corresponding eigenvector are calculated, and the eigenvector is normalized to be the weight vector. After calculation, the maximum eigenvalue of the comparison matrix consisting of the evaluation indexes is 8.125 , and the corresponding eigenvectors are $[0.205,0.161,0.164,0.070,0.069,0.073,0.088$, and $0.179]$. Thus, the corresponding weight values for the evaluation indexes of rock mass quality are shown in Table 7.

(4) Determining whether the comparison matrix satisfies the consistence test. If it does not, go back and redo the pairwise comparison matrix. Usually, the consistency ratio $\mathrm{CR}$ is used to measure the quality of 
TABLE 1: A list of influencing factors considered in typical rock mass classification methods.

\begin{tabular}{|c|c|c|c|c|c|c|c|c|}
\hline Method & RSR & RMR & Q & $Z$ & YZP & ET & $\begin{array}{c}\text { China national } \\
\text { standard }\end{array}$ & $\begin{array}{c}\text { Number of } \\
\text { factors }\end{array}$ \\
\hline Proposed age & 1972 & 1973 & 1974 & 1979 & 1985 & 1985 & 1994 & \\
\hline $\begin{array}{l}\text { Number of joint } \\
\text { sets }\end{array}$ & & & $\sqrt{ }$ & & & & & 1 \\
\hline Joint spacing & $\sqrt{ }$ & $\sqrt{ }$ & $\sqrt{ }$ & & $\sqrt{ }$ & $\sqrt{ }$ & $\sqrt{ }$ & 6 \\
\hline Joint state & $\sqrt{ }$ & $\sqrt{ }$ & $\sqrt{ }$ & & $\sqrt{ }$ & $\sqrt{ }$ & $\sqrt{ }$ & 6 \\
\hline RQD & & $\sqrt{ }$ & $\sqrt{ }$ & & $\sqrt{ }$ & $\sqrt{ }$ & $\sqrt{ }$ & 5 \\
\hline $\begin{array}{l}\text { Rock mass } \\
\text { structure }\end{array}$ & & & & $\sqrt{ }$ & & & & 1 \\
\hline Integrity & & $\sqrt{ }$ & & $\sqrt{ }$ & $\sqrt{ }$ & $\sqrt{ }$ & $\sqrt{ }$ & 5 \\
\hline Weathering & & & & & $\sqrt{ }$ & $\sqrt{ }$ & $\sqrt{ }$ & 3 \\
\hline In situ stress & & & $\sqrt{ }$ & & & $\sqrt{ }$ & $\sqrt{ }$ & 3 \\
\hline Groundwater & $\sqrt{ }$ & $\sqrt{ }$ & $\sqrt{ }$ & & $\sqrt{ }$ & $\sqrt{ }$ & $\sqrt{ }$ & 6 \\
\hline $\begin{array}{l}\text { Geological } \\
\text { structure }\end{array}$ & $\sqrt{ }$ & & & & & & & 1 \\
\hline Rock strength & $\sqrt{ }$ & $\sqrt{ }$ & $\sqrt{ }$ & $\sqrt{ }$ & $\sqrt{ }$ & $\sqrt{ }$ & $\sqrt{ }$ & 7 \\
\hline $\begin{array}{l}\text { Joint shear } \\
\text { strength }\end{array}$ & & & & $\sqrt{ }$ & $\sqrt{ }$ & $\sqrt{ }$ & & 3 \\
\hline $\begin{array}{l}\text { Rock mass } \\
\text { deformation } \\
\text { modulus }\end{array}$ & & & & & $\sqrt{ }$ & $\sqrt{ }$ & & 2 \\
\hline $\begin{array}{l}\text { Rock } \\
\text { deformation } \\
\text { model }\end{array}$ & & & & & $\sqrt{ }$ & & & 1 \\
\hline $\begin{array}{l}\text { Rock mass elastic } \\
\text { wave velocity }\end{array}$ & & & & $\sqrt{ }$ & $\sqrt{ }$ & & $\sqrt{ }$ & 3 \\
\hline $\begin{array}{l}\text { Rock wave } \\
\text { velocity }\end{array}$ & & & $\sqrt{ }$ & $\sqrt{ }$ & $\sqrt{ }$ & $\sqrt{ }$ & $\sqrt{ }$ & 5 \\
\hline Joint orientation & $\sqrt{ }$ & $\sqrt{ }$ & & $\sqrt{ }$ & $\sqrt{ }$ & & $\sqrt{ }$ & 5 \\
\hline $\begin{array}{l}\text { Construction } \\
\text { method }\end{array}$ & & & & $\sqrt{ }$ & & & & 1 \\
\hline $\begin{array}{l}\text { Classification } \\
\text { grade }\end{array}$ & 5 grades & 5 grades & 9 grades & 5 grades & 5 grades & 5 grades & 5 grades & \\
\hline $\begin{array}{l}\text { Engineering } \\
\text { application }\end{array}$ & $\begin{array}{l}\text { Tunnel } \\
\text { support }\end{array}$ & $\begin{array}{l}\text { Tunnel } \\
\text { mining }\end{array}$ & $\begin{array}{l}\text { Tunnel } \\
\text { cavern }\end{array}$ & $\begin{array}{c}\text { Dam foundation of } \\
\text { underground } \\
\text { engineering }\end{array}$ & $\begin{array}{c}\text { Rock mass of } \\
\text { dam } \\
\text { foundation }\end{array}$ & $\begin{array}{c}\text { Rock mass of } \\
\text { dam } \\
\text { foundation }\end{array}$ & $\begin{array}{l}\text { Underground } \\
\text { and ground slope }\end{array}$ & \\
\hline
\end{tabular}

TABLE 2: Quantitative table for the evaluation index of rock mass quality.

\begin{tabular}{|c|c|c|c|c|c|c|c|}
\hline Roughness & $\begin{array}{l}\text { Quantitative } \\
\text { value }\end{array}$ & Aperture & $\begin{array}{l}\text { Quantitative } \\
\text { value }\end{array}$ & Weathering & $\begin{array}{l}\text { Quantitative } \\
\text { value }\end{array}$ & Groundwater & $\begin{array}{l}\text { Quantitative } \\
\text { value }\end{array}$ \\
\hline Toothed rough & 1 & Tightly close & 1 & Fresh & 1 & Dry & 1 \\
\hline $\begin{array}{l}\text { Toothed slightly } \\
\text { rough }\end{array}$ & 2 & Close & 2 & $\begin{array}{c}\text { Slightly } \\
\text { weathered }\end{array}$ & 2 & Moist & 2 \\
\hline Toothed smooth & 3 & Microopen & 3 & $\begin{array}{l}\text { Moderately } \\
\text { weathered }\end{array}$ & 3 & Wet & 3 \\
\hline Wavy rough & 4 & Open & 4 & $\begin{array}{c}\text { Highly } \\
\text { weathered }\end{array}$ & 4 & Soaking water & 4 \\
\hline $\begin{array}{l}\text { Wavy slightly } \\
\text { rough }\end{array}$ & 5 & $\begin{array}{l}\text { Medium } \\
\text { open }\end{array}$ & 5 & $\begin{array}{l}\text { Completely } \\
\text { weathered }\end{array}$ & 5 & Dripping & 5 \\
\hline Wavy smooth & 6 & Wide open & 6 & & & Linear drip & 6 \\
\hline Flat rough & 7 & & & & & $\begin{array}{l}\text { Flowing } \\
\text { water }\end{array}$ & 7 \\
\hline $\begin{array}{l}\text { Flat slightly } \\
\text { rough }\end{array}$ & 8 & & & & & & \\
\hline Flat smooth & 9 & & & & & & \\
\hline
\end{tabular}




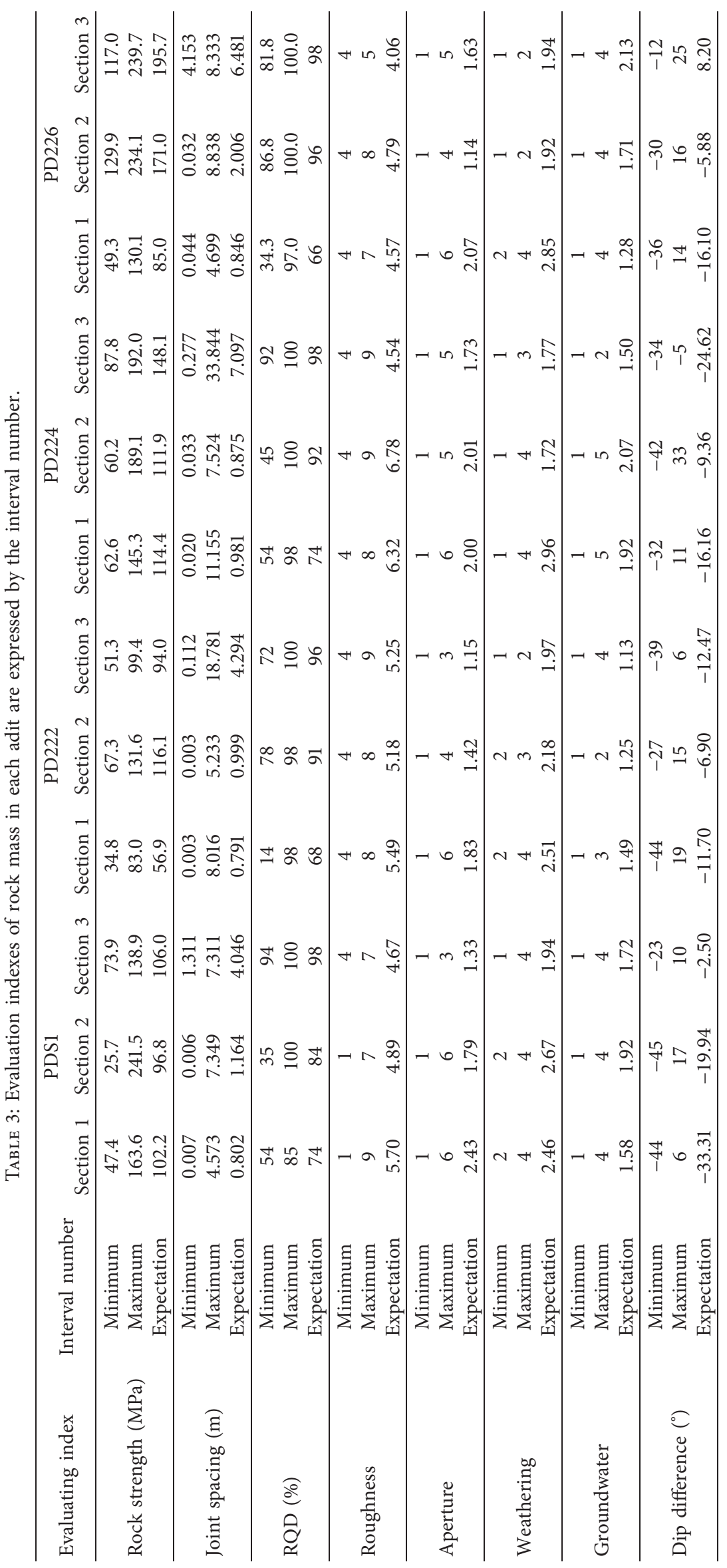


TABLE 4: Classification standard for the evaluation index of rock mass quality $[8,10,18]$.

\begin{tabular}{|c|c|c|c|c|c|}
\hline \multirow{2}{*}{ Evaluating index } & \multicolumn{5}{|c|}{ Classification grade of rock mass } \\
\hline & 1 & 2 & 3 & 4 & 5 \\
\hline Rock strength (MPa) & $250 \sim 1000$ & $100 \sim 250$ & $50 \sim 100$ & $25 \sim 50$ & $0 \sim 25$ \\
\hline Joint spacing $(\mathrm{m})$ & $3 \sim 100$ & $1 \sim 3$ & $0.3 \sim 1$ & $0.05 \sim 0.3$ & $0 \sim 0.05$ \\
\hline RQD (\%) & $90 \sim 100$ & $75 \sim 90$ & $50 \sim 75$ & $25 \sim 50$ & $0 \sim 25$ \\
\hline Roughness & $1 \sim 3$ & $3 \sim 5$ & $5 \sim 7$ & $7 \sim 8$ & $8 \sim 9$ \\
\hline Aperture & $1 \sim 2$ & $2 \sim 3$ & $3 \sim 4$ & $4 \sim 5$ & $5 \sim 6$ \\
\hline Weathering & $1 \sim 1.5$ & $1.5 \sim 2.0$ & $2.0 \sim 2.5$ & $2.5 \sim 3.0$ & $3.0 \sim 4.0$ \\
\hline Groundwater & $1 \sim 2$ & $2 \sim 3$ & $3 \sim 4$ & $4 \sim 5$ & $5 \sim 7$ \\
\hline Dip difference $\left({ }^{\circ}\right)$ & $20 \sim 35$ & $5 \sim 20$ & $-5 \sim 5$ & $-20 \sim-5$ & $-35 \sim-20$ \\
\hline
\end{tabular}

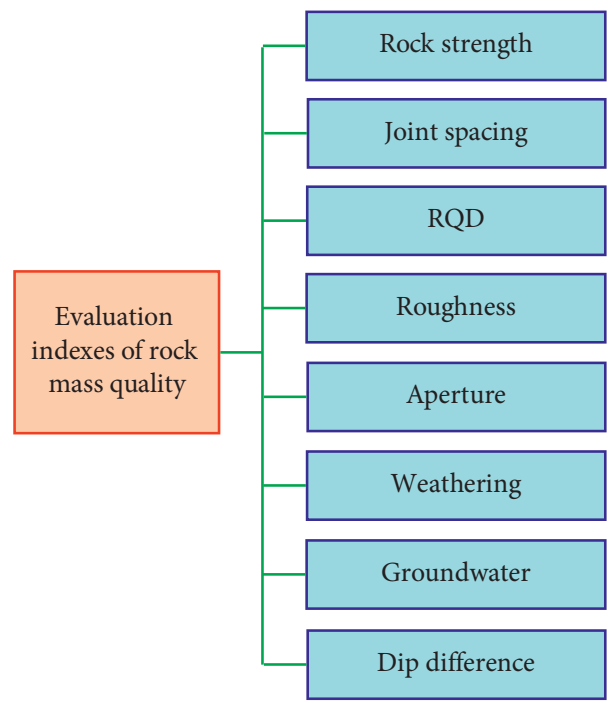

Figure 8: The hierarchical structural model of rock mass classification.

TABle 5: The fundamental scale of AHP (Saaty [36]).

\begin{tabular}{|c|c|c|}
\hline $\begin{array}{l}\text { Intensity of } \\
\text { importance }\end{array}$ & Definition & Explanation \\
\hline 1 & Equal importance & Two activities contribute equally to the objective \\
\hline 2 & Weak & - \\
\hline 3 & Moderate prevalence of one over another & $\begin{array}{c}\text { Experience and judgment slightly favor one } \\
\text { activity over another }\end{array}$ \\
\hline 4 & Moderate plus & - \\
\hline 5 & Strong or essential prevalence & $\begin{array}{c}\text { Experience and judgment strongly favor one } \\
\text { activity over another }\end{array}$ \\
\hline 6 & Strong plus & - \\
\hline 7 & Very strong or demonstrated prevalence & $\begin{array}{l}\text { An activity is favored very strongly over another; } \\
\text { its dominance demonstrated in practice }\end{array}$ \\
\hline 8 & Very very strong & - \\
\hline 9 & Extremely high prevalence & $\begin{array}{c}\text { The evidence favoring one activity over another is } \\
\text { of the highest possible order of affirmation }\end{array}$ \\
\hline $\begin{array}{l}\text { Reciprocals of } \\
\text { above }\end{array}$ & $\begin{array}{l}\text { If activity } i \text { has one of the above nonzero numbers assigned to it } \\
\text { when compared with activity } j \text {, then } j \text { has the reciprocal value when } \\
\text { compared with } i\end{array}$ & A reasonable assumption \\
\hline Rational & Ratios arising from the scale & $\begin{array}{c}\text { If consistency were to be forced by obtaining } n \\
\text { numerical values to span the matrix }\end{array}$ \\
\hline
\end{tabular}

judgment made by decision makers. When $\mathrm{CR}<0.1$, the logical consistency of judgment thinking is very good and the weight value determined by its comparison matrix is reasonable. When $\mathrm{CR}>0.1$, there are contradictions in logical thinking, and it is necessary to readjust the quantitative value of the 
TABLE 6: The pairwise comparison matrix for the evaluation index of rock mass quality.

\begin{tabular}{lcccccccc}
\hline Evaluation index & Rock strength & Joint spacing & RQD & Roughness & Aperture & Weathering & Groundwater & Dip difference \\
\hline Rock strength & 1 & 1 & 2 & 3 & 3 & 3 & 2 & 1 \\
Joint spacing & 1 & 1 & 1 & 2 & 2 & 2 & 3 & 2 \\
RQD & $1 / 2$ & 1 & 1 & 2 & 3 & 1 & 1 & 1 \\
Roughness & $1 / 3$ & $1 / 2$ & $1 / 2$ & 1 & 1 & 1 & 1 \\
Aperture & $1 / 3$ & $1 / 2$ & $1 / 3$ & 1 & 1 & 1 & 1 \\
Weathering & $1 / 3$ & $1 / 2$ & $1 / 3$ & 1 & 1 & 1 & $1 / 2$ \\
Groundwater & $1 / 2$ & $1 / 2$ & $1 / 2$ & 2 & 1 & 2 & $1 / 2$ \\
Dip difference & 1 & 1 & 1 & 2 & 3 & 2 & 2 & 1 \\
\hline
\end{tabular}

TABLe 7: Weight values for the evaluation index of rock mass quality.

\begin{tabular}{lcccccccc}
\hline Evaluation index & Rock strength & Joint spacing & RQD & Roughness & Aperture & Weathering & Groundwater & Dip difference \\
\hline Weight value & 0.205 & 0.161 & 0.164 & 0.070 & 0.069 & 0.073 & 0.088 & 0.179 \\
\hline
\end{tabular}

TABLE 8: The random consistency index (Saaty [36]).

\begin{tabular}{ccccccccccc}
\hline$N$ & 1 & 2 & 3 & 4 & 5 & 6 & 7 & 8 & 9 & 10 \\
\hline RI & 0 & 0 & 0.58 & 0.90 & 1.12 & 1.24 & 1.32 & 1.41 & 1.45 & 1.49 \\
\hline
\end{tabular}

TABLE 9: The results of rock mass classification.

\begin{tabular}{|c|c|c|c|c|c|c|c|c|}
\hline Adit & & $\mu_{m, 1}$ & $\mu_{m, 2}$ & $\mu_{m, 3}$ & $\mu_{m, 4}$ & $\mu_{m, 5}$ & The new method & RMR \\
\hline \multirow{3}{*}{ PDS1 } & Section 1 & -0.6274 & -0.2493 & -0.1340 & -0.7609 & -0.7917 & 3 & 3 \\
\hline & Section 2 & -0.5128 & -0.1044 & -0.3711 & -0.6929 & -0.8059 & 2 & 2 \\
\hline & Section 3 & -0.1627 & -0.1954 & -0.4255 & -0.8725 & -1.0000 & 1 & 1 \\
\hline \multirow{3}{*}{ PD222 } & Section 1 & -0.7333 & -0.4018 & 0.0750 & -0.3143 & -0.9226 & 3 & 3 \\
\hline & Section 2 & -0.3733 & -0.2808 & -0.2873 & -0.7541 & -0.9785 & 2 & 2 \\
\hline & Section 3 & -0.3369 & -0.4101 & -0.4705 & -0.6273 & -0.9153 & 1 & 1 \\
\hline \multirow{3}{*}{ PD224 } & Section 1 & -0.6548 & -0.2621 & -0.2503 & -0.6012 & -0.8064 & 3 & 3 \\
\hline & Section 2 & -0.4100 & -0.1616 & -0.3240 & -0.6396 & -0.9506 & 2 & 2 \\
\hline & Section 3 & -0.0830 & -0.1375 & -0.7674 & -0.8562 & -0.7253 & 1 & 1 \\
\hline \multirow{3}{*}{ PD226 } & Section 1 & -0.7835 & -0.3276 & 0.0173 & -0.4693 & -0.8231 & 3 & 3 \\
\hline & Section 2 & -0.1145 & 0.0437 & -0.5225 & -0.8101 & -0.9900 & 2 & 2 \\
\hline & Section 3 & -0.0648 & 0.1669 & -0.6793 & -1.0000 & -1.0000 & 2 & 2 \\
\hline
\end{tabular}

relative importance of each factor in the comparison matrix. The consistency ratio $\mathrm{CR}$ can be calculated according to the following formula:

$$
\mathrm{CR}=\frac{\mathrm{CI}}{\mathrm{RI}}
$$

where RI is a random consistency index, which was given by Saaty, as shown in Table 8, and CI is a consistency index and can be calculated according to the following formula:

$$
\mathrm{CI}=\frac{\lambda_{\max }-N}{N-1}
$$

where $\lambda_{\max }$ is the maximum eigenvalue of the comparison matrix and $N$ is the order of the comparison matrix.

After calculation, the consistency ratio $C R$ of the comparison matrix is 0.0127 , which is obviously less than 0.1 . It shows that the logical consistency of the comparison matrix is good, and the weight value calculated by the comparison matrix is reasonable.

3.5. Determination of Rock Mass Quality Grade. Firstly, the interval number expectation of each index in the sample to be evaluated and the evaluation criteria are calculated according to formula (1). Secondly, each index of the sample to be evaluated and the evaluation classification criteria are integrated into a set pair, and the connectional expectation for each index is calculated. Since rock strength, joint spacing, RQD, and dip difference belong to cost-type indexes, the corresponding connectional expectation is calculated according to formula (3). The other indexes are benefit-type indexes, and the connectional expectation can be calculated according to formula (4). Then, combined with the weight value of each index, the integrated connectional expectation of each sample to be evaluated with respect to 


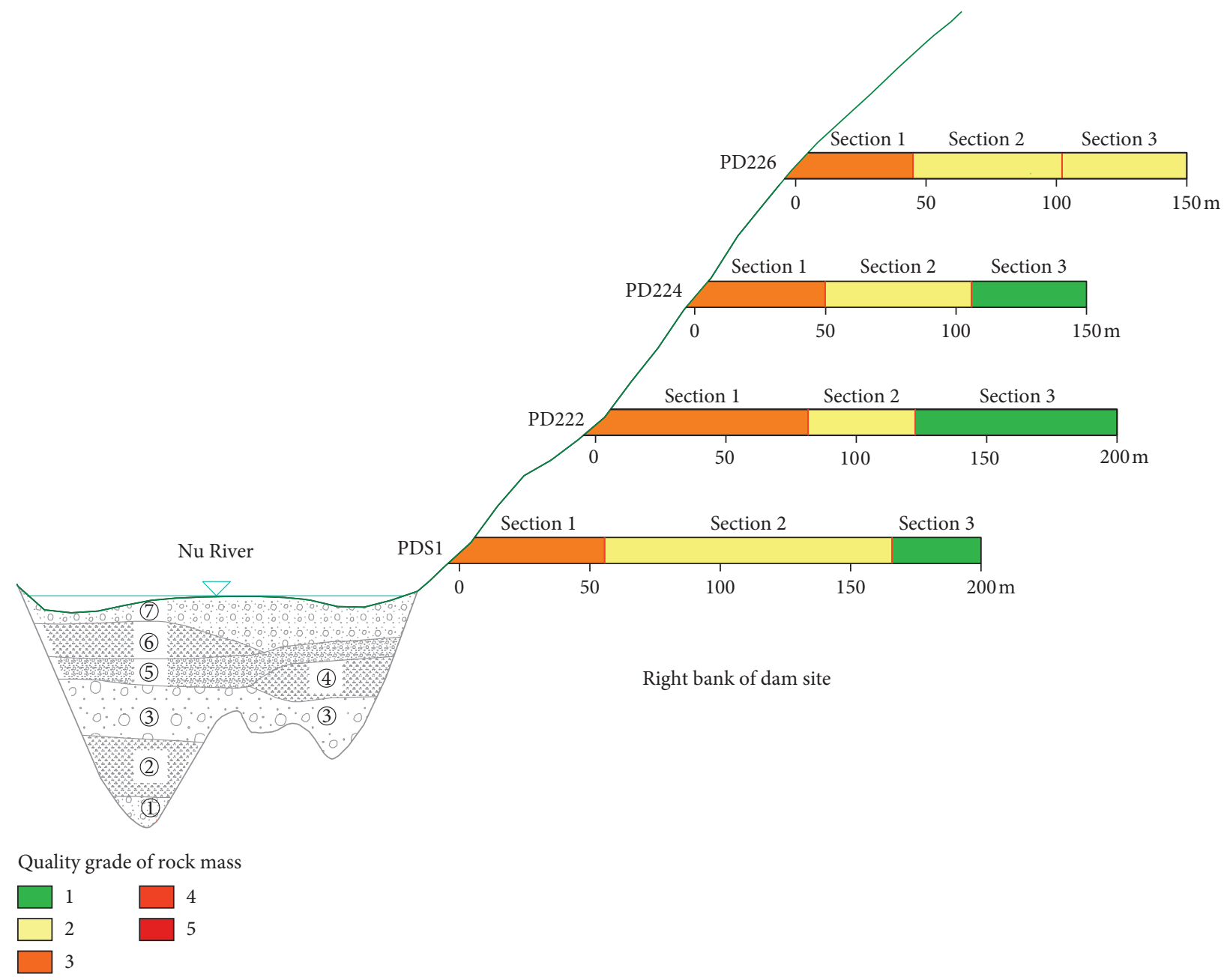

Figure 9: Spatial division of rock mass quality in the Songta dam site.

the evaluation grade $k$ is calculated according to formula (5). Finally, the evaluation grade of each sample to be evaluated is determined according to formula (6); that is, the grade corresponding to the maximum value of integrated connectional expectation is the classification grade of rock mass.

The integrated connectional expectations of the section 1 in adit PDS1 with respect to the evaluation grades $1,2,3,4$, and 5 are $-0.6274,-0.2493,-0.1340,-0.7609$, and -0.7917 , respectively. It is shown that the integrated connectional expectation of the section 1 in adit PDS1 with respect to the grade 3 of rock mass quality is the largest. Therefore, the rock mass quality of the section 1 in adit PDS1 is classified as grade 3. Similarly, the classification results of the new method in other homogeneous regions are shown in Table 9.

To verify the reliability of the new method, the RMR method is selected as the benchmark. The classification results of rock mass quality obtained by the new method are in accordance with the actual situation and are consistent with the results provided by the RMR classification. The comparison results show that the new method is reliable and can easily deal with the evaluation indexes of rock mass classification expressed by the interval number. In order to more intuitively display the classification results of the
Songta dam abutment rock mass, a spatial division map of rock mass quality is drawn as shown in Figure 9.

\section{Conclusions}

The stochastic joints developed within the rock mass are the key factors affecting rock mass quality. Besides, the geometric, mechanical, and hydraulic properties of stochastic joints usually change in a certain range. Hence, using interval numbers to represent the influencing factors of rock mass quality can not only reduce uncertainty, but also make the evaluation results more reasonable.

This paper introduces a comprehensive method to classify the rock mass with complex joints. Firstly, interval number theory is adopted to represent the evaluation indexes of rock mass quality. Secondly, analytic hierarchy process is utilized to determine the weight values of evaluation indexes. Thirdly, set pair analysis theory is used to analyze the connectional expectation between interval numbers and determine the quality grade of rock mass. The new method combines three mathematical methods to solve complex decision-making problems affected by various uncertainties, which can not only describe the dynamic 
evolution trend of various influencing factors, but also simplify the analysis process of the relationship between interval numbers.

The new method is applied to evaluate the quality grade of Songta dam abutment rock mass. The classification results of rock mass quality obtained by the new method are in accordance with the actual situation and are consistent with the results provided by the RMR classification. The quality grade of the section 1 in adits PDS1, PD222, PD224, and PD226 is grade 3 . The quality grade of the section 2 in adits PDS1, PD222, PD224, and PD226 and the section 3 in adit PD226 is grade 2. The quality grade of the section 3 in adits PDS1, PD222, and PD224 is grade 1.

\section{Data Availability}

The data used to support this research article are available from the first author on request.

\section{Conflicts of Interest}

The authors declare that there are no conflicts of interest regarding the publication of this paper.

\section{Acknowledgments}

This work was supported by the National Natural Science of China (Grant no. 41702301), Opening fund of State Key Laboratory of Geohazard Prevention and Geoenvironment Protection (Chengdu University of Technology) (Grant no. SKLGP2018K017), and Key Project of NSFC-Yunnan Joint Fund (Grant no. U1702241).

\section{References}

[1] T. Ramamurthy, "A geo-engineering classification for rocks and rock masses," International Journal of Rock Mechanics and Mining Sciences, vol. 41, no. 1, pp. 89-101, 2004.

[2] X. Zhou, J. P. Chen, Y. K. Ruan et al., "Demarcation of structural domains in fractured rock masses using a threeparameter simultaneous analysis method," Advances in Civil Engineering, vol. 2018, no. 6, Article ID 9358098, 13 pages, 2018.

[3] Y. Liu, Q. Wang, J. P. Chen et al., "Determination of geometrical REVs based on volumetric fracture intensity and statistical tests," Applied Sciences, vol. 8, no. 5, Article ID 8050800, 800 pages, 2018.

[4] L. Zhang, "Estimating the strength of jointed rock masses," Rock Mechanics and Rock Engineering, vol. 43, no. 4, pp. 391-402, 2010.

[5] Q. Jiang, B. Yang, F. Yan et al., "New method for characterizing the shear damage of natural rock joint based on $3 \mathrm{D}$ engraving and 3D scanning," International Journal of Geomechanics, vol. 2020, no. 2, Article ID 06019022, 2020.

[6] X. W. Hu and R. Q. Huang, "A simple discussion on quality classification of the rock mass in a water conservancy and hydroelectric project," Journal of Chengdu University of Technology, vol. 23, no. 3, pp. 64-68, 1996.

[7] K. Terzaghi, "Rock defects and loads on tunnel supports," in Rock Tunneling with Steel Supports, pp. 15-99, Commercial Shearing and Stamping Company, Youngstown, OH, USA, 1946.
[8] D. U. Deere, "Technical description of rock cores for engineering purposes," Rock Mechanics and Engineering Geology, vol. 1, no. 1, pp. 16-22, 1964.

[9] G. E. Wickham, H. R. Tiedemann, and E. H. Skinner, "Support determination based on geologic predictions," in Proceedings of conference on rapid excavation and tunneling, pp. 43-64, Chicago, IL, USA, June 1972.

[10] Z. T. Bieniawski, "Engineering classification of jointed rock masses," Siviele Ingenieurswese, vol. 15, no. 12, pp. 335-343, 1973.

[11] Z. T. Bieniawski, "Geomechanics classification of rock masses and its application in tunneling," in Proceedings of the $3 \mathrm{rd}$ International Congress on Rock Mechanics, ISRM, Denver, Colorado, pp. 27-32, September 1974.

[12] N. Barton, R. Lien, and J. Lunde, "Engineering classification of rock masses for the design of tunnel support," Rock Mechanics Felsmechanik Mecanique des Roches, vol. 6, no. 4, pp. 189-236, 1974.

[13] K. Kikuchi, K. Saito, and K. I. Kusonoki, "Geotechnically integrated evaluation on the stability of dam foundation rocks," in Proceedings of the 14th international congress on large dams, pp. 49-74, Rio de Janerio, Brazil, May 1982.

[14] D. Z. Gu and D. C. Huang, "Classification of rock mass structure and determination of its quality coefficient," Hydrogeology \& Engineering Geology, vol. 2, pp. 10-15, 1979.

[15] Z. W. Yang, Engineering Classification of Rock Mass-Theory and Practice of Rock Mechanics, China Water Power Press, Beijing, China, 1981.

[16] Z. M. Ren, Research on Dam Foundation Rock Mass Engineering of Three Gorges Project, China University of Geosciences Press, Beijing, China, 1998.

[17] China Planning Press, "National Standards Compilation Group of People's Republic of China GB 50218-94," in Standard for Engineering Classification of Rock Masses, China Planning Press, Beijing, China, 1994.

[18] China Planning Press, National Standards Compilation Group of People's Republic of China GB 50287-99, Code for Water Resources and Hydropower Engineering Geological Investigation, China Planning Press, Beijing, China, 1999.

[19] L. Y. He, Discussion of General Research Route to Value the Rock Mass Mechanical Parameters of Dam Foundation, Lanzhou University, Lanzhou, China, 2009.

[20] Q. Jiang, G. Su, X.-t. Feng, G. Chen, M.-z. Zhang, and C. Liu, "Excavation optimization and stability analysis for large underground caverns under high geostress: a case study of the Chinese Laxiwa project," Rock Mechanics and Rock Engineering, vol. 52, no. 3, pp. 895-915, 2018.

[21] Y. J. Wei, Study on Characteristics of Rock Mass Structure and Engineering Application of Emeishan Basalts in Project Site of Hydroelectric Power Station in Southwestern China, Chengdu University of Technology, Chengdu, China, 2007.

[22] S. G. Zhang, Engineering Geological Feasibility Study of High Arch Dam Construction at Baihetan Hydropower Station, Jinsha River, Chengdu University of Technology, Chengdu, China, 2007.

[23] G. Habibagahi and S. Katebi, "Rock mass classification using fuzzy set theory," Iranian Journal of Science and Technology, vol. 20, no. 3, pp. 273-284, 1996.

[24] G. H. Yuan, J. P. Chen, and L. Ma, "Application of extenics in evaluating of engineering quality of rock mass," Chinese Journal of Rock Mechanics and Engineering, vol. 24, no. 9, pp. 1539-1544, 2005.

[25] W. G. Cao and Y. J. Zhang, "Study on two-stage fuzzy synthetic judgment method with changing weight value for rock 
quality classification in underground structures," Chinese Journal of Rock Mechanics and Engineering, vol. 25, no. 8, pp. 1612-1618, 2006.

[26] Q. Z. Hu and W. H. Zhang, Research and Application of Interval Number Theory, Science Press, Beijing, China, 2010.

[27] A. Sengupta and T. K. Pal, "On comparing interval numbers," European Journal of Operational Research, vol. 127, no. 1, pp. 28-43, 2000.

[28] M. X. Song, W. Jiang, C. H. Xie et al., "A new interval numbers power average operator in multiple attribute decision making," International Journal of Intelligent Systems, vol. 32, pp. 631-644, 2016.

[29] K. Q. Zhao, Set Pair Analysis and its Preliminary Application, Zhejiang Science and Technology Press, Hangzhou, China, 2000.

[30] M.-W. Wang, P. Xu, J. Li, and K.-Y. Zhao, "A novel set pair analysis method based on variable weights for liquefaction evaluation," Natural Hazards, vol. 70, no. 2, pp. 1527-1534, 2014.

[31] J. Hu and L. Yang, "Dynamic stochastic multi-criteria decision making method based on cumulative prospect theory and set pair analysis," Systems Engineering Procedia, vol. 1, no. 1, pp. 432-439, 2011.

[32] M. W. Wang, K. Y. Zhao, and L. B. Zhang, "A novel evaluation model based on connectional expectation for swellingshrinkage grade of untreated and treated expansive clay," Chinese Journal of Rock Mechanics and Engineering, vol. 36, no. 8, pp. 1553-1557, 2014.

[33] R. Q. Huang, F. Lin, D. J. Chen et al., "Formation mechanism of unloading fracture zone of high slopes and its engineering behaviors," Journal of Engineering Geology, vol. 9, no. 3, pp. 227-232, 2001.

[34] S. Song, Q. Wang, J. Chen, Y. Li, W. Zhang, and Y. Ruan, "Fuzzy C-means clustering analysis based on quantum particle swarm optimization algorithm for the grouping of rock discontinuity sets," KSCE Journal of Civil Engineering, vol. 21, no. 4, pp. 1115-1122, 2017.

[35] T. L. Saaty, "A scaling method for priorities in hierarchical structures," Journal of Mathematical Psychology, vol. 15, no. 3, pp. 234-281, 1977.

[36] T. L. Saaty, The Analytic Hierarchy Process, McGraw-Hill International Book Company, New York, NY, USA, 1980.

[37] Y.-C. Liu and C.-S. Chen, "A new approach for application of rock mass classification on rock slope stability assessment," Engineering Geology, vol. 89, no. 2, pp. 129-143, 2007. 